$\therefore$ NASA TECHNICAL MEMORANDUM
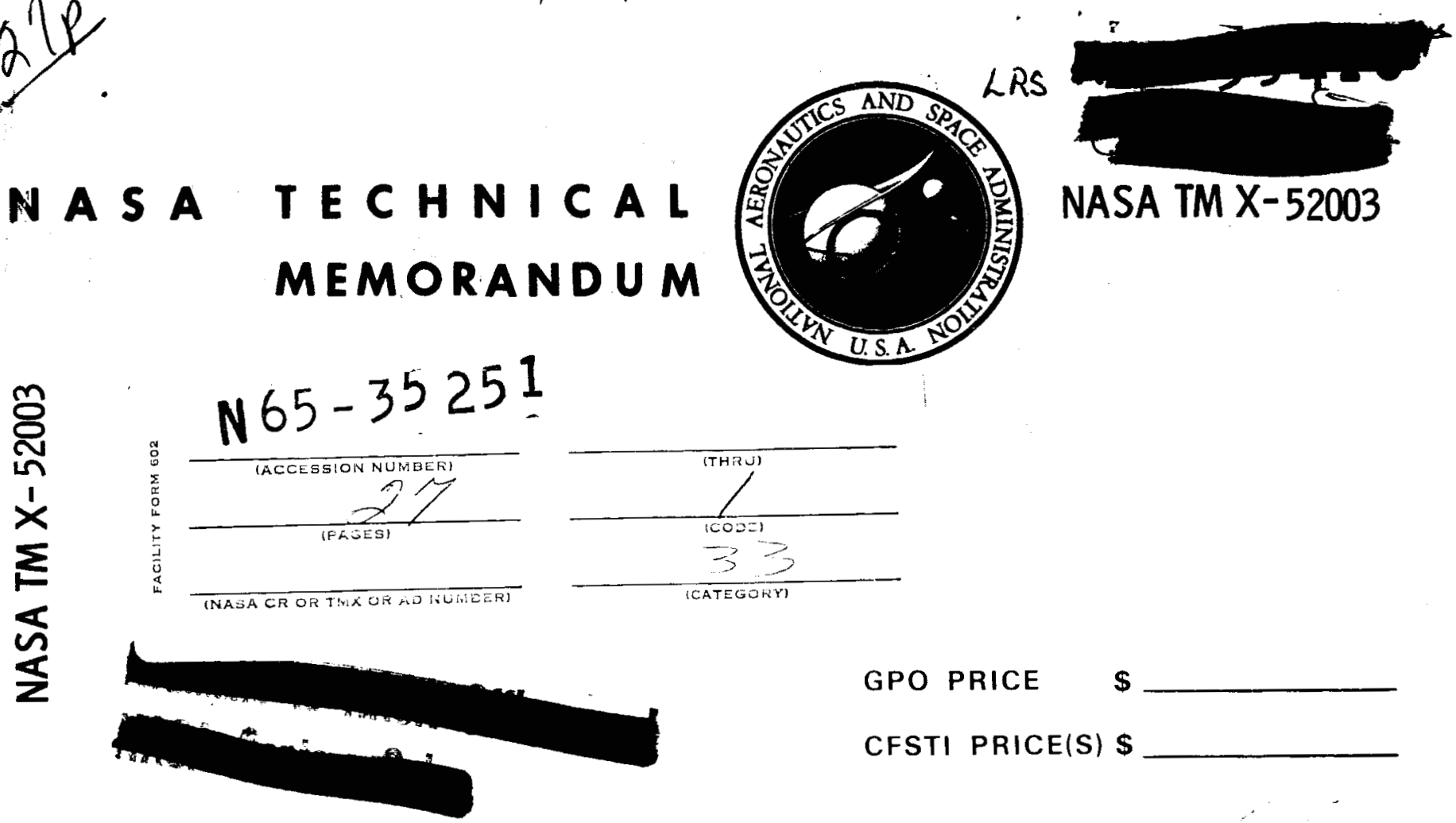

NASA TM X-52003

Hard copy $(\mathrm{HC})$

Microfiche (MF)

ff 653 July 65

\title{
ANALYTIC SOLUTIONS TO THE IGNITION KINETICS OF THE HYDROGEN=OXYGEN REACTION
}

by Richard S. Brokaw

Lewis Research Center

Cleveland, Ohio

TECHNICAL PREPRINT prepared for Tenth International

Symposium on Combustion sponsored by the Combustion

Institute and the Cambridge Physical Chemistry Department

Cambridge, England, (August 17-21, 1964)

NATIONAL AERONAUTICS AND SPACE ADMINISTRATION - WASHINGTON, D.C. 1964 
$1-26-03$

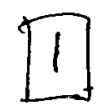

TECHNICAL MEMORANDUM

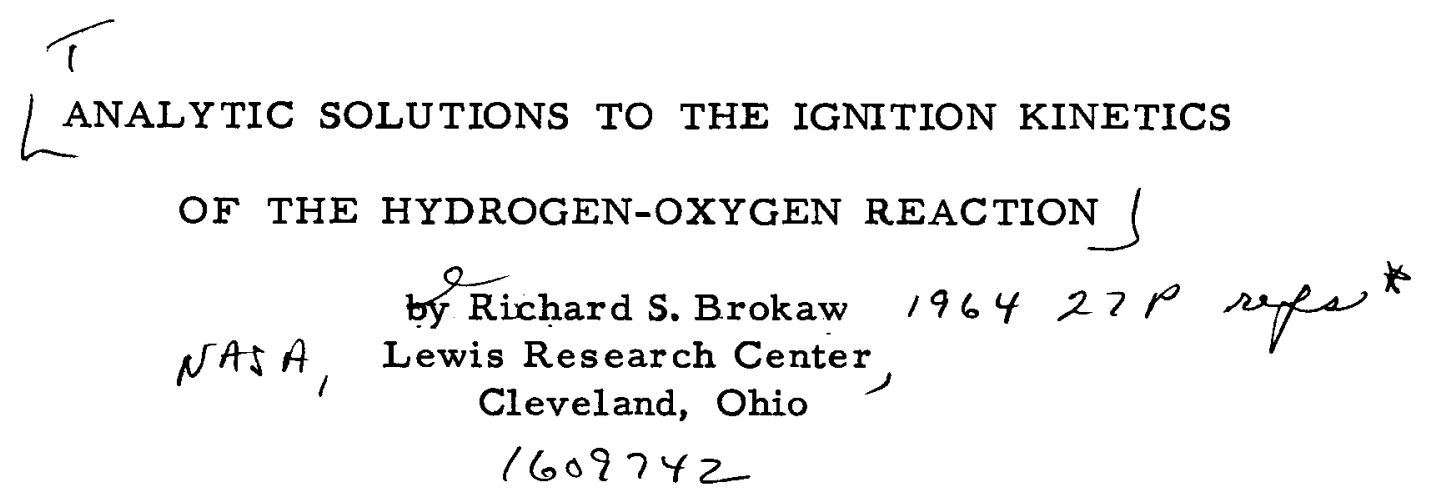

1 Corf.

* TECHI PREPRINT prepared for $<10$ Th

Tenth Intern Symp on Combustims

sponsored by the Combusti Inst and a

Cambridge Physical Chemi Dep

Gumber London, Augut 7-2I, 1964

Une.

(NASATMX-52003)

NATIONAL AERONAUTICS AND SPACE ADMINISTRATION 


\title{
ANALYTIC SOLUTIONS TO THE IGNITION KINETICS
}

OF THE HYDROGEN-OXYGEN REACTION

\author{
by Richard S. Brokaw \\ Lewis Research Center \\ National Aeronautics and Space Administration \\ Cleveland, Ohio \\ SUMMARY

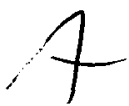

Solutions have been obtained assuming isothermal conditions and negligible depletion of reactants during the induction period for the following scheme of reactions:

$$
\begin{gathered}
\mathrm{OH}+\mathrm{H}_{2} \stackrel{\mathrm{k}_{1}}{\longrightarrow} \mathrm{H}_{2} \mathrm{O}+\mathrm{H} \\
\mathrm{H}+\mathrm{O}_{2} \stackrel{\mathrm{k}_{2}}{\longrightarrow} \mathrm{OH}+\mathrm{O} \\
\mathrm{O}+\mathrm{H}_{2} \stackrel{\mathrm{k}_{3}}{\longrightarrow} \mathrm{OH}+\mathrm{H} \\
\mathrm{H}+\mathrm{O}_{2}+\mathrm{M} \stackrel{\mathrm{k}_{6}}{\longrightarrow} \mathrm{HO}_{2}+\mathrm{M} \\
\mathrm{HO}_{2}+\mathrm{H}_{2} \stackrel{\mathrm{k}_{11}}{\longrightarrow} \mathrm{H}_{2} \mathrm{O}_{2}+\mathrm{H}
\end{gathered}
$$

Three types of solutions have been deduced, corresponding to $k_{6} c_{M}>2 k_{2}$ (a low-temperature - high-pressure region of long ignition delays), $2 \mathrm{k}_{2}>\mathrm{k}_{6} \mathrm{~cm}$ (a high-temperature - low-pressure region of short delays), and $2 \mathrm{k}_{2}=\mathrm{k}_{6} \mathrm{c}_{\mathrm{M}}$ (the boundary between the two regions). Experimental ignition delays in both long and short delay regions are adequately explained, and ignition delays computed by numerical integration of the rate equations are reproduced to with a few percent. Finally, ignition delays for the Von Neumann spike condition in Chapman-Jouguet detonations 
in the neighborhood of the leam limit of detonability in air have been calculated. These delays decrease by two orders of magnitude as the hydrogen mole fraction increases from 0.135 to 0.145 . This is very close to the experimental limit (hydrogen mole fraction 0.14 to 0.15 ) and thus supports the notion that the condition $2 \mathrm{k}_{2}>\mathrm{k}_{6} \mathrm{c}_{\mathrm{M}}$ must be satisfied for a stable detonation.

\section{INTRODUCTION}

When hydrogen and air are instantaneously mixed at high temperature (as in idealized analyses pertinent to hypersonic ramjets ${ }^{1}{ }^{2}$ ), or when a mixture containing hydrogen and oxygen is subjected to a pulse of high temperature and pressure (as in shock tube ignition studies ${ }^{3,4}$ ), the following events ensue: First, there is a very short period during which small concentrations of atoms and radicals - $\mathrm{H}, \mathrm{OH}$, and $\mathrm{O}$ - are produced. The mechanism of this initiation is uncertain and may vary under different circumstances. There follows the bulk of the induction period during which the chain reaction is propagated and branched through the elementary reactions

$$
\begin{gathered}
\mathrm{OH}+\mathrm{H}_{2} \stackrel{\mathrm{k}_{1}}{\longrightarrow} \mathrm{H}_{2} \mathrm{O}+\mathrm{H} \\
\mathrm{H}+\mathrm{O}_{2} \stackrel{\mathrm{k}_{2}}{\longrightarrow} \mathrm{OH}+\mathrm{O} \\
\mathrm{O}+\mathrm{H}_{2} \stackrel{\mathrm{k}_{3}}{\longrightarrow} \mathrm{OH}+\mathrm{H}
\end{gathered}
$$

The first reaction is not strongly exothermic (i.e., 15 kilocalories at $\left.1000^{\circ} \mathrm{K}\right)$, while the second and third reactions are endothermic by 16 and 2 kilocalories, respectively. Thus, during most of the induction period, 
the atom and radical concentrations increase exponentially under essentially isothermal conditions. Very late in the induction period, atom and radical concentrations become so large that self-heating occurs, largely due to the highly exothermic three-body recombination processes. The temperature rises precipitously, and the induction period is at an end.

At the lower temperatures and higher pressures the further reactions

$$
\begin{array}{ll}
\mathrm{H}+\mathrm{O}_{2}+\mathrm{M} \stackrel{\mathrm{k}_{6}}{\longrightarrow} \mathrm{HO}_{2}+\mathrm{M} & \mathrm{VI} \\
\mathrm{HO}_{2}+\mathrm{H}_{2} \stackrel{\mathrm{K}_{\mathrm{II}}}{\longrightarrow} \mathrm{H}_{2} \mathrm{O}_{2}+\mathrm{H} & \mathrm{XI}
\end{array}
$$

must be considered as well. These five reactions, together with terms describing the destruction of chain carriers after diffusion to the walls, suffice to explain qualitatively the ignition behavior of the hydrogenoxygen system, including the existence of the first, second, and third explosion limits.

The differential equations describing the chemical kinetics of reactions I, II, and III have been integrated numerically for hypersonic ramjet $^{1,2}$ and shock tube ${ }^{4}$ conditions. This paper presents analytic solutions that are excellent approximations to the numerical results; furthermore, reactions VI and XI have been included. These analytic solutions are valuable in that they permit one to determine easily the effects of variations in specific rate constants, temperature, pressure, initiation mechanism, etc., on ignition delays and the like. Some illustrative applications are presented and discussed. 
THEORETICAL CONSIDERATIONS

The differential equations governing the growth of radical concentrations during the induction period are as follows:

$$
\begin{aligned}
& \frac{d c_{\mathrm{OH}}}{\mathrm{dt}}=-\mathrm{k}_{1} \mathrm{c}_{2} \mathrm{C}_{\mathrm{OH}}+\mathrm{k}_{2} \mathrm{c}_{2} \mathrm{c}_{\mathrm{H}}+\mathrm{k}_{3} \mathrm{c}_{\mathrm{H}_{2}} \mathrm{c}_{\mathrm{O}}+i_{\mathrm{OH}} \\
& \frac{d c_{H}}{d t}=k_{1} c_{H_{2}} c_{O H}-k_{2} c_{2} c_{H}+k_{3} c_{H_{2}} c_{O}-k_{6} c_{2} c_{M} c_{H}+k_{11} c_{H_{2}} c_{H_{2}}+i_{H} \\
& \frac{d c_{O}}{d t}=k_{2} c_{2} c_{H}-k_{3} c_{H_{2}} c_{O}+i_{O} \\
& \frac{d \mathrm{c}_{\mathrm{HO}}}{d t}=\mathrm{k}_{6} \mathrm{c}_{2} \mathrm{c}_{\mathrm{M}} \mathrm{c}_{\mathrm{H}}-\mathrm{k}_{11} \mathrm{c}_{2} \mathrm{CHO}_{2}+i_{\mathrm{HO}_{2}}
\end{aligned}
$$

Here, the $k^{\prime} s$ are the specific reaction rate constants, the $c^{\prime} s$ are concentrations, and the $i^{\prime} s$ are rates at which the radicals are generated spontaneously, either in the gas phase or on the surfaces. (It is also possible to include destruction of radicals at the walls by including terms like $r_{\mathrm{W}} \mathrm{c}_{\mathrm{OH}}$, etc. in Eqs. (1) to (4), with the coefficient $\gamma_{\mathrm{W}}$ a function of diffusivity, pressure, geometry, and surface activity.)

During most of the induction period, the kinetics of the elementary reactions I to III, VI, and XI can be represented as pseudo first-order reactions; that is, they are all first order in the atom and radical concentrations - the only concentrations that are changing appreciably.

The initiation rates $i_{\mathrm{OH}}$, etc., which are zero order in the radical concentrations, can be eliminated from Eqs. (1) to (4) by means of the substitutions 5

$$
c_{\mathrm{OH}}^{\prime} \equiv c_{\mathrm{OH}}+\frac{i_{\mathrm{H}}+i_{\mathrm{O}}+i_{\mathrm{HO}_{2}}}{k_{1} c_{\mathrm{H}_{2}}}
$$




$$
\begin{gathered}
c_{\mathrm{H}}^{\prime} \equiv c_{\mathrm{H}}+\frac{i_{\mathrm{OH}}+i_{\mathrm{H}}+2 i_{\mathrm{O}}+i_{\mathrm{HO}_{2}}}{2 \mathrm{k}_{2} \mathrm{c}_{2}} \\
c_{\mathrm{O}}^{\prime} \equiv c_{\mathrm{O}}+\frac{i_{\mathrm{OH}}+i_{\mathrm{H}}+i_{\mathrm{HO}}}{2 \mathrm{k}_{3} \mathrm{c}_{2}} \\
c_{\mathrm{HO}_{2}}^{\prime} \equiv c_{\mathrm{HO}_{2}}+\frac{\mathrm{k}_{6} \mathrm{c}_{\mathrm{M}}}{2 \mathrm{k}_{2} \mathrm{k}_{11} \mathrm{c}_{2}}\left[i_{\mathrm{OH}}+i_{\mathrm{H}}+2 i_{\mathrm{O}}+\left(1-\frac{2 \mathrm{k}_{2}}{\mathrm{k}_{6} \mathrm{c}_{\mathrm{M}}}\right) i_{\mathrm{HO}_{2}}\right]
\end{gathered}
$$

These initiation rates are presumably very small compared with the rates of reactions I to III, so that the correction terms of Eqs. (5) to (8) are negligible except in the very initial portion of the induction period. Consequently, in what follows, these corrections will be neglected. They should be considered, however, in any detailed analysis of the kinetics of initiation. Inclusion of these terms poses no mathematical problem they simply increase algebraic complexity.

The system of differential equations (Eqs. (1) to (4)) may be solved by the method outlined by Frost and Pearson ${ }^{6}$, assuming that the concentrations of reactants $-\mathrm{H}_{2}, \mathrm{O}_{2}$, and $\mathrm{M}$ - are constant and neglecting $i_{\mathrm{OH}}, i_{\mathrm{H}}$, io, and $i_{\mathrm{HO}_{2}}$ (or applying Eqs. (5) to (8)). A set of particular solutions is

$$
c_{i}=A_{i} e^{\lambda t} \quad i=O H, H, O, \mathrm{HO}_{2}
$$

Substituting Eqs. (9) into Eqs. (1) to (4) yields the relations 


$$
\begin{array}{cc}
-\left(\mathrm{k}_{1} \mathrm{c}_{\mathrm{H}}+\lambda\right) \mathrm{A}_{\mathrm{OH}} & +\mathrm{k}_{2} \mathrm{c}_{2} \mathrm{~A}_{\mathrm{H}}+\mathrm{k}_{3} \mathrm{c}_{\mathrm{H}_{2}} \mathrm{~A}_{\mathrm{O}} \\
\mathrm{k}_{1} \mathrm{c}_{\mathrm{H}_{2}} \mathrm{~A}_{\mathrm{OH}}-\left(\mathrm{k}_{2} \mathrm{c}_{2}+\mathrm{k}_{6} \mathrm{c}_{2} \mathrm{c}_{\mathrm{M}}+\lambda\right) \mathrm{A}_{\mathrm{H}}+\mathrm{k}_{3} \mathrm{c}_{\mathrm{H}_{2}} \mathrm{~A}_{\mathrm{O}}+\mathrm{k}_{11} \mathrm{c}_{\mathrm{H}_{2}} \mathrm{~A}_{\mathrm{HO}_{2}} & =0 \\
\mathrm{k}_{2} \mathrm{c}_{2} \mathrm{~A}_{\mathrm{H}}-\left(\mathrm{k}_{3} \mathrm{c}_{\mathrm{H}_{2}}+\lambda\right) \mathrm{A}_{\mathrm{O}} & =0 \\
\mathrm{k}_{6} \mathrm{c}_{2} \mathrm{c}_{\mathrm{M}} \mathrm{A}_{\mathrm{H}} & -\left(\mathrm{k}_{11} \mathrm{c}_{\mathrm{H}_{2}}+\lambda\right) \mathrm{A}_{\mathrm{HO}_{2}}=0
\end{array}
$$

A nontrivial solution requires that the determinant of the coefficients of the $A_{i}$ be $z e r 0^{6}$. This leads to the quartic equation

$$
\begin{aligned}
\lambda^{4}+\left[\left(\mathrm{k}_{1}+\mathrm{k}_{3}\right.\right. & \left.\left.+\mathrm{k}_{11}\right) \mathrm{c}_{\mathrm{H}_{2}}+\left(\mathrm{k}_{2}+\mathrm{k}_{6} \mathrm{c}_{\mathrm{M}}\right) \mathrm{c}_{\mathrm{O}_{2}}\right] \lambda^{3} \\
& +\left[\mathrm{k}_{1} \mathrm{k}_{3} \mathrm{c}_{\mathrm{H}_{2}}^{2}+\left(\mathrm{k}_{1}+\mathrm{k}_{3}\right) \mathrm{k}_{6} \mathrm{c}_{\mathrm{H}_{2}} \mathrm{c}_{2} \mathrm{c}_{\mathrm{M}}+\left(\mathrm{k}_{1} \mathrm{c}_{\mathrm{H}_{2}}+\mathrm{k}_{2} \mathrm{c}_{\mathrm{O}_{2}}+\mathrm{k}_{3} \mathrm{c}_{\mathrm{H}_{2}}\right) \mathrm{k}_{11} \mathrm{c}_{\mathrm{H}_{2}}\right] \lambda^{2} \\
& +\mathrm{k}_{1} \mathrm{k}_{3} \mathrm{c}_{\mathrm{H}_{2}}^{2}\left[\left(\mathrm{k}_{6} \mathrm{c}_{\mathrm{M}}-2 \mathrm{k}_{2}\right) \mathrm{c}_{\mathrm{O}_{2}}+\mathrm{k}_{11} \mathrm{c}_{\mathrm{H}_{2}}\right] \lambda-2 \mathrm{k}_{1} \mathrm{k}_{2} \mathrm{k}_{3} \mathrm{k}_{11} \mathrm{c}_{\mathrm{H}_{2}}^{3} \mathrm{c}_{2}=0
\end{aligned}
$$

We seek the positive roots of this equation, which govern the exponential growth of radical concentrations during the induction period. The negative roots are transients important only in the initiation phases of the reaction - they quickly die out.

The rate constant $k_{11}$ is very small in comparison with $k_{1}, k_{2}, k_{3}$, and $\mathrm{k}_{6} \mathrm{c}_{\mathrm{M}}$. Therefore, the additive terms involving $\mathrm{k}_{11}$ in the coefficients of $\lambda$, $\lambda^{2}$, and $\lambda^{3}$ may be neglected.

We shall derive positive roots of Eq. (14) for three conditions:

$$
\mathrm{k}_{6} \mathrm{c}_{\mathrm{M}}>2 \mathrm{k}_{2}, \mathrm{k}_{6} \mathrm{c}_{\mathrm{M}}=2 \mathrm{k}_{2} \text {, and } \mathrm{k}_{6} \mathrm{c}_{\mathrm{M}}<2 \mathrm{k}_{2} \text {. }
$$


$\mathrm{k}_{6 . \mathrm{M}}>2 \mathrm{k}_{2}$. This regime corresponds to the conditions above the third explosion limit. This is a region of long ignition lags, with delays of several seconds at $560^{\circ}$ to $600^{\circ} \mathrm{C}$ and atmospheric pressure. Correspondingly, the positive $\lambda$ is very small and we find that $\lambda^{2}, \lambda^{3}$, and $\lambda^{4}$ may be set equal to zero in Eq. (14). Thus, we obtain

$$
\lambda \cong \frac{2 \mathrm{k}_{2} \mathrm{k}_{11} \mathrm{c}_{2}}{\mathrm{k}_{6} \mathrm{c}_{\mathrm{M}}-2 \mathrm{k}_{2}}
$$

This expression is a very good approximation indeed, except very close to the second limit condition where the denominator approaches zero. Note that, at high pressure, $\lambda \rightarrow 2 \mathrm{k}_{2} \mathrm{k}_{11} \mathrm{c}_{\mathrm{H}_{2}} / \mathrm{k}_{6} \mathrm{c}_{\mathrm{M}}$, which is independent of pressure.

$\mathrm{k}_{6} \mathrm{c}_{\mathrm{M}}=2 \mathrm{k}_{2}$ (Second limit condition). Above the junction of the second and third limits, this condition marks the boundary between regions of long and short ignition delay. Here, the coefficient of $\lambda$ in Eq. (14) is zero (neglecting the term in $\mathrm{k}_{1 l}$ ). We may neglect $\lambda^{3}$ and $\lambda^{4}$ relative to $\lambda^{2}$ to obtain

$$
\lambda \cong\left[\frac{2 \mathrm{k}_{1} \mathrm{k}_{2} \mathrm{k}_{3} \mathrm{k}_{11} \mathrm{c}_{\mathrm{H}_{2}}^{2} \mathrm{c}_{2}}{\mathrm{k}_{1} \mathrm{k}_{3} \mathrm{c}_{\mathrm{H}_{2}}+\left(\mathrm{k}_{1}+\mathrm{k}_{3}\right) \mathrm{k}_{6} \mathrm{c}_{\mathrm{O}_{2} \mathrm{c}_{\mathrm{M}}}}\right]^{1 / 2}
$$

$2 k_{2}>k_{6} c_{M}$. This corresponds to the important region of short ignition delays at high temperatures and modest pressures. Under these conditions, the coefficient of $\lambda$ in Eq. (14) becomes negative, all terms involving $\mathrm{k}_{11}$ may be neglected, and Eq. (14) reduces to the cubic equation

$$
\lambda=\frac{k_{1} k_{3}\left(2 k_{2}-k_{6} c_{M}\right) c_{H_{2}}^{2} c_{O_{2}}}{k_{1} k_{3} c_{H_{2}}^{2}+\left(k_{1}+k_{3}\right) k_{6} c_{H_{2}} c_{O_{2}} c_{M}+\left[\left(k_{1}+k_{3}\right) c_{H_{2}}+\left(k_{2}+k_{6} c_{M}\right) c_{O_{2}}\right] \lambda+\lambda^{2}}
$$


Note that, if $\lambda$ is small, the terms involving $\lambda$ and $\lambda^{2}$ in the denominator are unimportant. If, in addition, $k_{1}, k_{2}$, and $k_{3}$ are much larger than $\mathrm{k}_{6} \mathrm{c}_{\mathrm{M}}, \lambda$ approaches $2 \mathrm{k}_{2} \mathrm{C}_{2}$. This provides the basis of the ignition delay correlation used by Schott and Kinsey. 3

Equation (17) has a further interesting aspect. Suppose we have an approximate value of $\lambda$, which we designate $\lambda_{1}$. We can use the right side of Eq. (17) to generate a second approximation, $\lambda_{2}$. We seek a positive root. Hence, if $\lambda_{1}$ is too small, $\lambda_{2}$ will be too large; if $\lambda_{1}$ is too large, $\lambda_{2}$ is too small. Thus, the correct solution is bracketed, and the approximation $\lambda \cong\left(\lambda_{1} \lambda_{2}\right)^{1 / 2}$ should be in error by less than half the error of the worst of the two estimates. *

An approximate solution can be obtained by invoking the steadystate approximation in $\mathrm{OH}$ (setting Eq. (1) equal to zero). Thus, Eq. (1) can be used to eliminate the $\mathrm{OH}$ concentration from Eqs. (2) and (3), which can then be solved with the result

$$
\lambda_{1}=\frac{k_{3} c_{H_{2}}+k_{6} c_{O_{2}} c_{M}}{2}\left\{\left[1+\frac{4 k_{3}\left(2 k_{2}-k_{6}{ }^{c}\right) c_{H_{2}}{ }^{{ }_{0} O_{2}}}{\left(k_{3} c_{H_{2}}+k_{6}{ }^{c_{0}}{ }_{2}{ }^{1 / 2}\right)^{2}}\right]^{1 /}\right\}
$$

This, in turn, may be substituted into Eq. (17) to obtain $\lambda_{2}$, so that the final approximation to $\lambda$ is:

*Note that if the error in $\lambda_{2}$ is less than twice the error in $\lambda_{1}$, the geometric mean value (call it $\lambda_{3}$ ) is clearly superior to $\lambda_{1}$. Thus, $\lambda_{3}$ can be substituted into Eq. (17) to obtain an improved approximation, $\lambda_{4} ; \lambda_{5} \equiv\left(\lambda_{3} \lambda_{4}\right)^{1 / 2}$ will be an improvement over $\lambda_{3} \equiv\left(\lambda_{1} \lambda_{2}\right)^{1 / 2}$. This provides an iterative procedure that will converge on the true value of $\lambda$. 
$\lambda \cong\left(\lambda_{1} \lambda_{2}\right)^{1 / 2}$

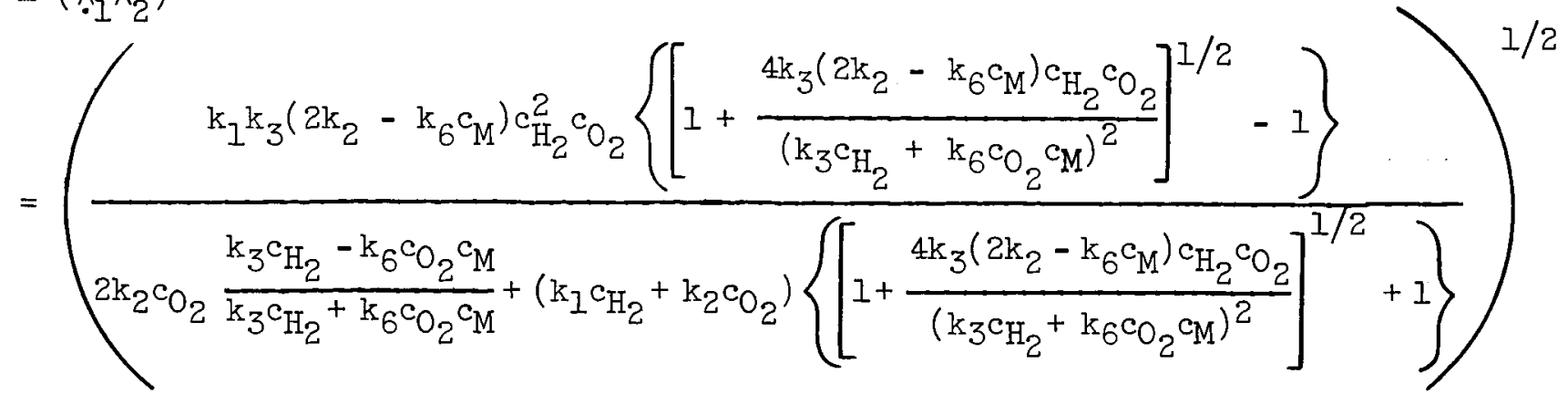

It is possible, of course, to obtain other first approximations $\lambda_{1}$ by assuming steady states in $\mathrm{H}$ or $\mathrm{O}$ rather than $\mathrm{OH}$. Some numerical comparisons with these other techniques are shown in table $I$ (taking $k_{6}=0$ ). The assumption of a steady state in $\mathrm{OH}$ gives clearly superior values of $\lambda_{1}$, although the final approximations $\left(\lambda_{1} \lambda_{2}\right)^{1 / 2}$ are remarkably good in all cases. The OH concentration is smallest, so it seems reasonable that the steady-state approximation should apply best to this radical. (The true values of $\lambda$ were obtained by numerical solution of Eq. (17).)

Once the value of $\lambda$ has been obtained, relations among $A_{O H}, A_{H}$, $A_{O}$, and $\mathrm{A}_{\mathrm{HO}}$ follow from Eqs. (10) to (13).

It remains merely to discuss the boundary conditions that define the beginning and end of the ignition delay period. We shall assume for simplicity that the initiation phase of the induction period is very short and may be neglected in comparison with the total span of the delay before ignition. (As indicated heretofore, it is possible to obtain analytic solutions without this assumption, but at the expense of algebraic complexity. Further, a detailed knowledge of the initiation kinetics would be required.) 
Let us assume that the initiation process produces radicals by some bimolecular process:

$$
i_{i}=\left(\frac{d c_{i}}{d t}\right)_{t=0} \propto c_{M}^{2}
$$

where $c_{M}$ represents the total concentration of stable species. Examples of reactions of this sort could include

$$
\begin{gathered}
\mathrm{H}_{2}+\mathrm{O}_{2} \longrightarrow 2 \mathrm{OH} \\
\mathrm{H}_{2}+\mathrm{O}_{2} \longrightarrow \mathrm{H}+\mathrm{HO}_{2} \\
\mathrm{H}_{2}+\mathrm{M} \longrightarrow 2 \mathrm{H}+\mathrm{M}
\end{gathered}
$$

and others as well. It is reasonable to assume that, initially, the rate of formation of radicals is equal to the rate of consumption in reactions such as I, II, and III, etc., (which are first order in the radical, but second order overall):

$$
\left(\frac{d c_{i}}{d t}\right)_{t=0} \propto c_{M} A_{i}
$$

where $A_{i}$ is an effective initial radical concentration (see (Eq. (9)). Thus, in general, from Eqs. (20) and (21),

$$
A_{i}=\text { const } c_{M}=a_{i} p
$$

so that the radical concentration as a function of time is

$$
c_{i}=a_{i} p e^{\lambda t}
$$

as long as initiation is in the gas phase and requires only a small fraction of the ignition delay.

The end of the induction period can be defined in a number of ways that are qualitatively equivalent. For example, Schott and Kinsey ${ }^{3}$ define 
the end of the delay period as the time at which the concentration of some species reaches a characteristic level (in their case, $c_{\mathrm{OH}}=10^{-6}$ moles liter $\left.{ }^{-1}\right)$. Thus, from Eq. (23),

$$
\lambda \tau=B-\ln p
$$

where $\tau$ is the ignition delay and $B$ is a constant. The same result is obtained if one characterizes the end of the delay period by a critical rate of temperature rise due to three-body radical recombination:

$$
c_{M} C_{p}\left(\frac{d T}{d t}\right)_{c r i t} \propto c_{i} c_{j} c_{M} \Delta H_{i j} \propto c_{M} p^{2} e^{2 \lambda \tau}
$$

which again leads to Eq. (24). Again, if one assumes a critical rate of temperature rise due to a bimolecular process such as reaction I, Eq. (24) follows once more. Thus, a variety of reasonable assumptions about the initiation and termination of the induction period all lead to expressions of the form of Eq. (24).

\section{ILLUSTRATIVE APPLICATIONS}

In this section, the foregoing theoretical results are applied to calculate ignition delays for hydrogen-air systems under a variety of conditions of practical interest including ( 1 ) the low-temperature region of moderate pressures, where ignition delays of one to several seconds are observed, (2) the higher-temperature low-to-moderate-pressure regime, where delays range from several microseconds to several milliseconds, and finally (3) the high-temperature - high-pressure boundary between these regimes, which seems to be of importance in determining limits of detonability. 
Region of long delays. Ignition delays for hydrogen in air were measured. some three decades ago by Dixon ${ }^{7}$ using an apparatus in which a heated stream of hydrogen was injected into a larger concentric stream of heated air. Interpolated delays at $600^{\circ} \mathrm{C}$ are shown in Fig. 1.

In this regime, the characteristic parameter $\lambda$ (used in Eq. (24) to compute the ignition delay $\tau$ ) is given by Eq. (15). From Fig. 1 it is clear that, at a pressure close to one-half atmosphere, the ignition delays become very short, corresponding to the condition $\mathrm{k}_{6} \mathrm{c}_{\mathrm{M}}=2 \mathrm{k}_{2}$. This provides a key for determining the effective hydrogen concentration (which is otherwise indeterminate in Dixon's experiment), because $k_{6}$ is a function of the nature of the third body, M. We assume

$$
\begin{aligned}
\mathrm{k}_{6}=3.27 \times 10^{15}\left(\mathrm{x}_{\mathrm{H}_{2}}+0.35 \mathrm{x}_{\mathrm{O}_{2}}+0.43 \mathrm{x}_{\mathrm{N}_{2}}+0.2 \mathrm{x}_{\mathrm{Ar}}\right. \\
\left.+14.3 \mathrm{x}_{\mathrm{H}_{2} \mathrm{O}}+. . .\right) \mathrm{T}^{-1.92} \quad \text { 1iters }{ }^{2} \mathrm{~mole}^{-2} \mathrm{sec}^{-1}
\end{aligned}
$$

where the $x^{2} s$ are the mole fractions of various third bodies. Equation (26) is consistent with $\mathrm{Clyne} \mathrm{s}^{8}$ room temperature measurement (with argon as a third body), and Baldwin's ${ }^{8}$ estimates at $540^{\circ} \mathrm{C}$. The relative third-body efficiencies are taken from reference 9 . Using $\mathrm{k}_{6}$ from Eq. (26) and $k_{2}$ from reference 4 we find that the effective mole fraction of hydrogen is 0.22 . This procedure may seem somewhat arbitrary, but it is comforting that the hydrogen mole fraction did not turn out to be negative (limit pressure $>0.66 \mathrm{~atm}$ ) or greater than unity (limit pressure $<0.27 \mathrm{~atm})$ !

The curve in Fig. 1, computed assuming $\mathrm{k}_{11}=5.2 \times 10^{2}$ liters mole $\mathrm{e}^{-1}$ $\sec ^{-1}$ and $B=3.8$, provides a very good fit of the experimental data. This 
value of $k_{l l}$ is greater than that suggested by Voevodsky ${ }^{10}$ by a factor of 4.5. The cause of this discrepancy is uncertain: Voevodsky perhaps deduced his $k_{11}$ assuming somewhat different values of $k_{2}$ and $k_{6}$; but, on the other hand, our kinetic scheme is probably oversimplified.

Other observations by Dixon ${ }^{7}$ are also easily understood from these theoretical relationships. Thus, he reported ignition delays in oxygen slightly shorter than those in air. This is not surprising since the oxygen concentration does not appear explicitly in Eq. (15); its only effect is to cause a slight decrease in $k_{6}$ (see Eq. (26)). On the other hand, Dixon reported markedly longer delays in the presence of water vapor. This is due to the fact that water is a very efficient third body, so that $k_{6}$ is considerably increased.

The effect of hydrogen concentration on the ignition delay has been determined by Anagnostou, Brokaw, and Butler; ${ }^{11}$ some of their results near $600^{\circ} \mathrm{C}$ are shown in Fig. 2. (They found some variation according to the mode of operation of their apparatus; the shortest delays at this temperature were roughly half as large as those shown in Fig. 2.) The curve in Fig. 2 has been calculated from Eqs. (15) and (24) with the same constants used to fit Dixon's data in Fig. 1. Thus, the experimental composition dependence is rather well predicted: $\tau \propto \mathrm{p}_{\mathrm{H}_{2}}^{-0.6}$.

It seems then that the analytic solutions presented in this paper describe the behavior of the hydrogen-oxygen reaction in the region of long delays rather well.

Region of short delays. Ignition delays for hydrogen-air have been calculated numerically by Momtchiloff, Taback, and Buswell, ${ }^{l}$ and Belles and 
Lauver ${ }^{4}$ using different assumptions as to the mechanism of initiation. Momtchiloff, Taback, and Buswell use Schott and Kinsey's ${ }^{3}$ criterion for ignition $\left(\mathrm{c}_{\mathrm{OH}}=10^{-6}\right.$ moles liter $\left.{ }^{-1}\right)$; Belles and Lauver ${ }^{4}$ give constants for Eq. (9) so that Schott and Kinsey's criterion is easily applied to their calculations as well. (Both papers neglect reaction VI.)

The analysis of reference 1, presumably pertinent to hypersonic ramjets, assumes equilibrium concentrations of hydrogen and oxygen atoms in the hydrogen and air streams prior to instantaneous mixing. The hydrogen atoms are expected to be more important because of their higher equilibrium concentration. Thus, the growth of $\mathrm{OH}$ radical concentration with time is

$$
c_{\mathrm{OH}}=c_{\mathrm{H}, \mathrm{Eq}} \frac{\mathrm{AOH}_{\mathrm{OH}}}{\mathrm{A}_{\mathrm{H}}} \mathrm{e}^{\lambda t}
$$

From Eqs. (10) and (11), neglecting reactions VI and XI, we obtain

$$
\frac{A_{O H}}{A_{H}}=\frac{2 k_{2} c_{O_{2}}+\lambda}{2 k_{1} c_{H_{2}}+\lambda}
$$

Thus, the induction times computed numerically in reference 1 can be approximated from Eqs. (19), (27), and (28). Numerical and approximate analytic results are compared in table II.

Belles and Lauver, ${ }^{4}$ on the other hand, assume initiation via the reaction

$$
\mathrm{H}_{2}+\mathrm{O}_{2} \stackrel{\mathrm{k}_{\mathrm{OH}}}{\longrightarrow} 2 \mathrm{OH}
$$

Assuming that, initially, the rate of production of $\mathrm{OH}$ radicals in this reaction equals the rate of their consumption in reaction $I$, we obtain

$$
\mathrm{A}_{\mathrm{OH}}=\frac{{ }^{2 \mathrm{k}_{\mathrm{OH}} \mathrm{O}_{2}}}{\mathrm{k}_{1}}
$$


so that the ignition delay is

$$
\lambda \tau=\ln \left(\frac{{ }^{\mathrm{C}} \mathrm{H}_{\mathrm{crit}}}{\mathrm{A}_{\mathrm{OH}}}\right)=\operatorname{In}\left(\frac{\mathrm{k}_{1} \times 10^{-6}}{2 \mathrm{k}_{\mathrm{OH}^{\mathrm{C}} \mathrm{O}_{2}}}\right)
$$

Numerical ${ }^{4}$ and analytic results from Eq. (30) are compared in table II. It is clear that the analytic solutions are very good approximations to the numerical results, both for very lean and stoichiometric conditions, and for two rather different assumptions as to the initial source of radicals.

By studying stationary hydrogen-air flames in a flow system, Fourél2 has obtained information on ignition delays in the region of short delays. Fouré heated flowing homogeneous fuel-air mixtures to a temperature somewhat below the point of spontaneous ignition. The mixture, traveling at a high subsonic velocity, then passed through a diffuser into a reaction tube. The velocity decrease to about 40 meters per second was accompanied by increases in temperature and pressure that rendered the mixtures spontaneously inflammable. Temperature and composition profiles were obtained by probing the extended reaction zone formed some distance downstream of the diffuser. The distance from the diffuser exit to the point of appreciable temperature rise provides an indication of ignition delay times; however, the choice of the diffuser exit as a zero point is somewhat arbitrary since reaction may actually start within the diffuser. Fouré's results are shown in Fig. 3. A millisecond scale has been added based on the assumption that the velocity in reaction tube was 40 meters per second.

Ignition delays computed from Eqs. (19) and (24) are shown by the curve in Fig. 3. The constant $B$ has been taken as 25 so as to fit the 
experimental data at the leaner compositions. The deviation of the two richest mole fractions suggests that there may have been considerable reaction in the diffuser under these conditions.

Fouré was unable to observe any temperature rise in his ignition tube below $910^{\circ} \mathrm{K}$. Since the tube was 1 meter long and the flow velocity was about 40 meters per second, this suggests an ignition delay in excess of 25 milliseconds. Assuming again that $B=25$, we compute an ignition delay of 54 milliseconds. At this condition the delay is extremely sensitive to the temperature - if the temperature is raised but $1^{\circ}$, the delay decreases to $40 \mathrm{milliseconds,} \mathrm{and} \mathrm{we} \mathrm{would} \mathrm{hence} \mathrm{predict}$ a $25-$ millisecond delay at $912^{\circ}$ or $913^{\circ} \mathrm{K}$. Thus, the present analysis predicts Fouré's lower temperature limit within $3^{\circ} \mathrm{K}$.

One further point merits some discussion. The ignition delays in the region of long delays were fit assuming $B \simeq 3.8$ at $600^{\circ} \mathrm{K}$, whereas the short delay data require $B \simeq 25$ at a temperature some $60^{\circ}$ higher. From Eqs. (20) to (25) it appears that

$$
B=-\ln \left(\frac{d c_{i}}{d t}\right)_{t=0}+2 \ln p+\text { const }
$$

so that a small value of $B$ indicates a large initiation rate and vice versa. Thus, it appears that the initiation mechanisms in the Iong and short delay regions are distinctly different, and the long delay initiation rate is larger by perhaps nine orders of magnitude (although this changes the delays by less than one order of magnitude). There is evidence 13 that hydrogen peroxide plays an important role in the initiation of the hydrogen-oxygen reaction in the neighborhood of the second limit. 
Hydrogen peroxide is produced in reaction XI, which is important principally in the long delay regime. Boundary between long and short delay regions (and limits of detonability). A stable detonation wave involves the coupling of a shock front with a rapid chemical heat release, which, in turn, sustains the shock. Thus, the heat release must occur rather close to the shock in a stable detonation.

Belles ${ }^{14}$ has proposed that, in the case of the hydrogen-oxygen reaction, the limits of detonability may be predicted by requiring that, in a stable detonation, the second limit condition $2 \mathrm{k}_{2} \geq \mathrm{k}_{6} \mathrm{c} M$ be satisfied in the Von Neumann spike accompanying the detonation front. (These conditions of temperature and pressure are calculable from the ChapmanJouguet detonation Mach number, and the adiabatic shock relations for the nonreacting gas at the same Mach number.) Using the second-limit criterion, Belles predicted lean and rich limits of detonability for hydrogen-oxygen and hydrogen-air in good agreement with experiment.

Belles applied the second-limit criterion under conditions of temperature $\left(\sim 1300^{\circ} \mathrm{K}\right)$ and pressure ( 20 atm) where hydrogen-oxygen and hydrogen-air mixtures invariably ignite spontaneously (in other words, at temperatures above the junction of the second and third explosion limits). Thus, he tacitly assumes that there is a "memory" of the second limit - a demarcation between regions of long and short delay.

To examine this notion further, ignition delays have been calculated for conditions around the lean limit of detonability for hydrogen-air mixtures. Chapmen-Jouguet Mach numbers were computed as described by Zeleznik 
and Gordon, 15 and then conditions immediately behind the shock were deduced using ideal shock relations for a gas of $\gamma=1.4 .^{16}$ For initial conditions of room temperature and atmospheric pressure with hydrogen concentrations of 12 to 16 percent in air, the Von Neumann spike pressures and temperatures are in the range of 16 to 20 atmospheres and $1100^{\circ}$ to $1300^{\circ} \mathrm{K}$. Delays have been computed from Eq. (30) with rate constants for the initiation reaction and reactions $I$, II, and III from reference 4. Rate constants for reaction VI were obtained from Eq. (26) and the constants for reaction $X I$ were taken as

$$
\mathrm{k}_{11}=5.4 \times 10^{8} \exp (-24,000 / \mathrm{RT}) \quad \text { liters mole } \mathrm{e}^{-1} \mathrm{sec}^{-1}
$$

which is simply 4.5 times the value suggested by Voevodsky. 10

Results are shown in Fig. 4. Clearly there is an abrupt decrease in ignition lag around a hydrogen mole fraction of 0.14 ; the ignition delay decreases by two orders of magnitude as the hydrogen concentration is increased 0.01. This provides further support for Belles' postulate that the condition $2 k_{2} \geq k_{6}{ }^{c} M$ must be satisfied for stable detonations in the hydrogen-oxygen system.

Experimentally, the lean limit of detonability of hydrogen-air mixtures lies in the range of 14 to 15 percent of hydrogen by volume. 17

\section{CONCLUDING REMARKS}

It is hoped that the examples discussed in the preceding section illustrate the usefulness of these analytic solutions as applied to a variety of problems. Further analysis of this sort may help uncover more detailed information on the hydrogen-oxygen reaction. Some other applications suggest themselves: 
1. The concentrations of labile intermediates - $\mathrm{H}, \mathrm{OH}, \mathrm{O}, \mathrm{HO}_{2}$, etc. can be computed as a function of time throughout the induction period. Thus, one can explore the feasibility of detecting these species experimentally - for instance, spectoscopically, or with EPR, or the mass spectrometer.

2. By analyzing experimental ignition delay data obtained under a variety of conditions, it should be possible to glean information as to the mechanism of initiation, that is, the process by which atoms and free radicals are first generated from the reactants (by analysis of the term B in Eq. (24)).

3. By computing delays near the low-pressure limits of detonability, it may be possible to gain insight as to the degree of coupling between shock front and reaction zone required in a stable detonation.

4. If need be, other chemical reactions may be added to the scheme. (This may be desirable particularly in the high-pressure - low-temperature region.) There is a restriction, however: reactions must be first order in the intermediates or products. Thus, reactions such as $\mathrm{H}+\mathrm{H}_{2} \mathrm{O}_{2} \longrightarrow \mathrm{H}_{2} \mathrm{O}+\mathrm{OH}$ cannot be considered.

5. Finally, the general method of attack used here should be useful in obtaining solutions to the kinetics for other isothermal branched chain explosions.

\section{ACKINOWLEDGMENT}

The author wishes to thank Mr. Frank E. Belles of Lewis Research Center for introducing this problem to him and for many helpful subsequent discussions. 
REFERENCES

1. Momtchiloff, I. N., Taback, E. D., and Buswell, R. F.: Ninth Symposium (International) on Combustion. Academic Press, 1963, p. 220.

2. Westenberg, A. A. : Hydrogen - Air Chemical Kinetic Calculations in Supersonic Flow. Applied Physics Laboratory, The John Hopkins University Report CM-1028, December 1962.

3. Schott, G. L., and Kinsey, J. L.s J. Chem. Phys., 29, 1177 (1958).

4. Belles, F. E., and Lauver, M. Ra J. Chem. Phys., 40, 415 (1964).

5. Nicholls, J. A., Adamson, T. C., Jr., and Morrison, R. B.: AIAA J 1, 2253 (1963).

6. Frost, A. A., and Pearson, R. G.: Kinetics and Mechanism, John Wiley \& Sons, New York, 1953, pp. 160-164.

7. Coward, H. F. (Work of H. B. Dixon), J. Chem. Soc. 1934, 1382.

8. Clyne, M. A. A. : Ninth Symposium (International) on Combustion. Academic Press, 1963, p. 211.

9. Lewis, B., and Von Elbe, G.: Combustion, Flames, and Explosions of Gases. Academic Press, New York, 1951, p. 34.

10. Voevodsky, V. V.: Seventh Symposium (International) on Combustion. Butterworths, 1959, p. 34.

1l. Anagnostou, E., Brokaw, R. S., and Butler, J. N.: Effect of Concentration on Ignition Delays for Various Fuel - Oxygen - Nitrogen Mixtures at Elevated Temperatures. NACA TN 3887, 1956.

12. Fouré, C.: Rech Aeron, No. 42, 33 (1954).

13. Baldwin, R. R., Doran, P., and Mayor, L.: Eighth Symposium (International) on Combustion. Williams and Wilkins, 1962, p. 103. 
14. Belles, F. E.: Seventh Symposium (International). Butterworths, 1959, p. 745 .

15. Zeleznik, F. J., and Gordon, S.: A General IBM 704 or 7090 Computer Program for Computation of Chemical Equilibrium Compositions, Rocket Performance, and Chapman-Jouguet Detonations. NASA TN D-1454, 1962 .

16. Ames Research Staff: Equations, Tables, and Charts for Compressible Flow. NACA Report 1135, 1953.

17. Gordon, W. E., Mooradian, A. J., and Harper, S. A.: Seventh Symposium (International). Butterworths, 1959, p. 752. 
TABLE I. - NUMERICAL COMPARISON OF VARIOUS APPROXIMATIONS TO THE PARAMETER $\lambda$

[5 Percent $\mathrm{H}_{2}$ in air; rate constants from ref. 4.]

\begin{tabular}{|c|c|c|c|}
\hline \multirow{4}{*}{$\begin{array}{l}\text { Steady } \\
\text { state } \\
\text { in - }\end{array}$} & \multirow{4}{*}{$\begin{array}{l}\lambda, \\
\sec ^{-1}\end{array}$} & \multicolumn{2}{|c|}{ Temperature, ${ }^{\circ} \mathrm{K}$} \\
\hline & & 1100 & 1900 \\
\hline & & \multicolumn{2}{|c|}{ Pressure, atm } \\
\hline & & 0.2307 & 0.4873 \\
\hline $\mathrm{OH}$ & $\begin{array}{l}\lambda_{1} \\
\lambda_{2} \\
\left(\lambda_{1} \lambda_{2}\right)^{1 / 2}\end{array}$ & $\begin{array}{l}2.67 \times 10^{4} \\
2.39 \\
2.526\end{array}$ & $\begin{array}{l}3.70 \times 10^{5} \\
2.02 \\
2.734\end{array}$ \\
\hline $\mathrm{H}$ & $\begin{array}{l}\lambda_{1} \\
\lambda_{2} \\
\left(\lambda_{1} \lambda_{2}\right)^{1 / 2}\end{array}$ & $\begin{array}{l}10.1 \times 10^{4} \\
0.685 \\
2.630\end{array}$ & $\begin{array}{l}4.58 \times 10^{5} \\
1.616 \\
2.720\end{array}$ \\
\hline $\begin{array}{l}0 \\
\cdots\end{array}$ & $\begin{array}{l}\lambda_{1} \\
\lambda_{2} \\
\left(\lambda_{1} \lambda_{2}\right)^{1 / 2}\end{array}$ & $\begin{array}{l}8.76 \times 10^{4} \\
0.793 \\
2.638\end{array}$ & $\begin{array}{l}16.8 \times 10^{5} \\
0.360 \\
2.460\end{array}$ \\
\hline & True value & $2.503 \times 10^{4}$ & $2.727 \times 10^{5}$ \\
\hline
\end{tabular}


TABLE II. - COMPARISON OF NUMERICAL AND APPROXTMATE

ANALYTIC CALCULATIONS OF HYDROGEN-

AIR IGNITION DELAYS

\begin{tabular}{|c|c|c|c|c|}
\hline $\begin{array}{c}\text { Temper- } \\
\text { ature, } \\
\mathrm{O}_{\mathrm{K}}\end{array}$ & $\begin{array}{c}\text { Pressure, } \\
\text { atm }\end{array}$ & $\begin{array}{c}\text { Mole frac- } \\
\text { tion of } \mathrm{H}_{2}\end{array}$ & \multicolumn{2}{|c|}{ Ignition delay, $\mu \mathrm{sec}$} \\
\cline { 3 - 5 } & $\begin{array}{c}\text { Approximate } \\
\text { (this paper) }\end{array}$ & Numerical \\
\hline 1673 & 1.0 & 0.296 & 240 & 260 (ref. 1) \\
1100 & 1.0 & .296 & 5.3 & 5.1 (ref. 1) \\
1900 & .2307 & .05 & 866 & $866 \quad$ (ref. 4) \\
.4873 & .05 & 33.6 & 32.6 (ref. 4) \\
\hline
\end{tabular}




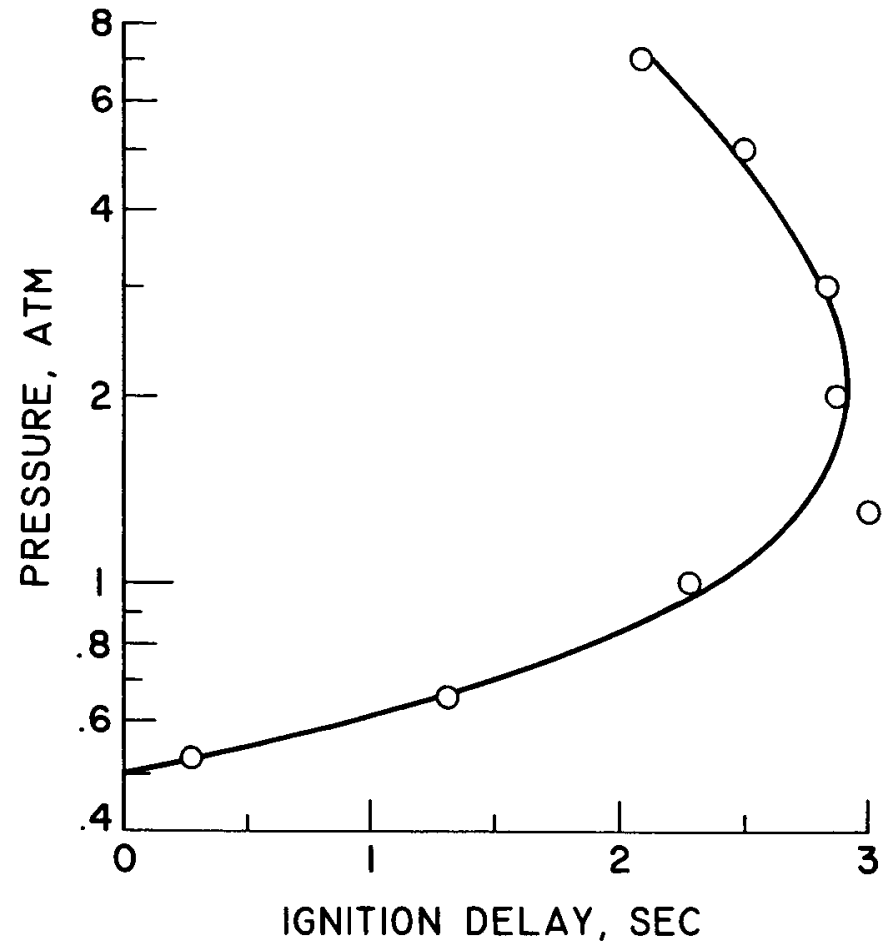

Fig. 1. - Effect of pressure on hydrogen-air ignition delays at $600^{\circ} \mathrm{C}$.

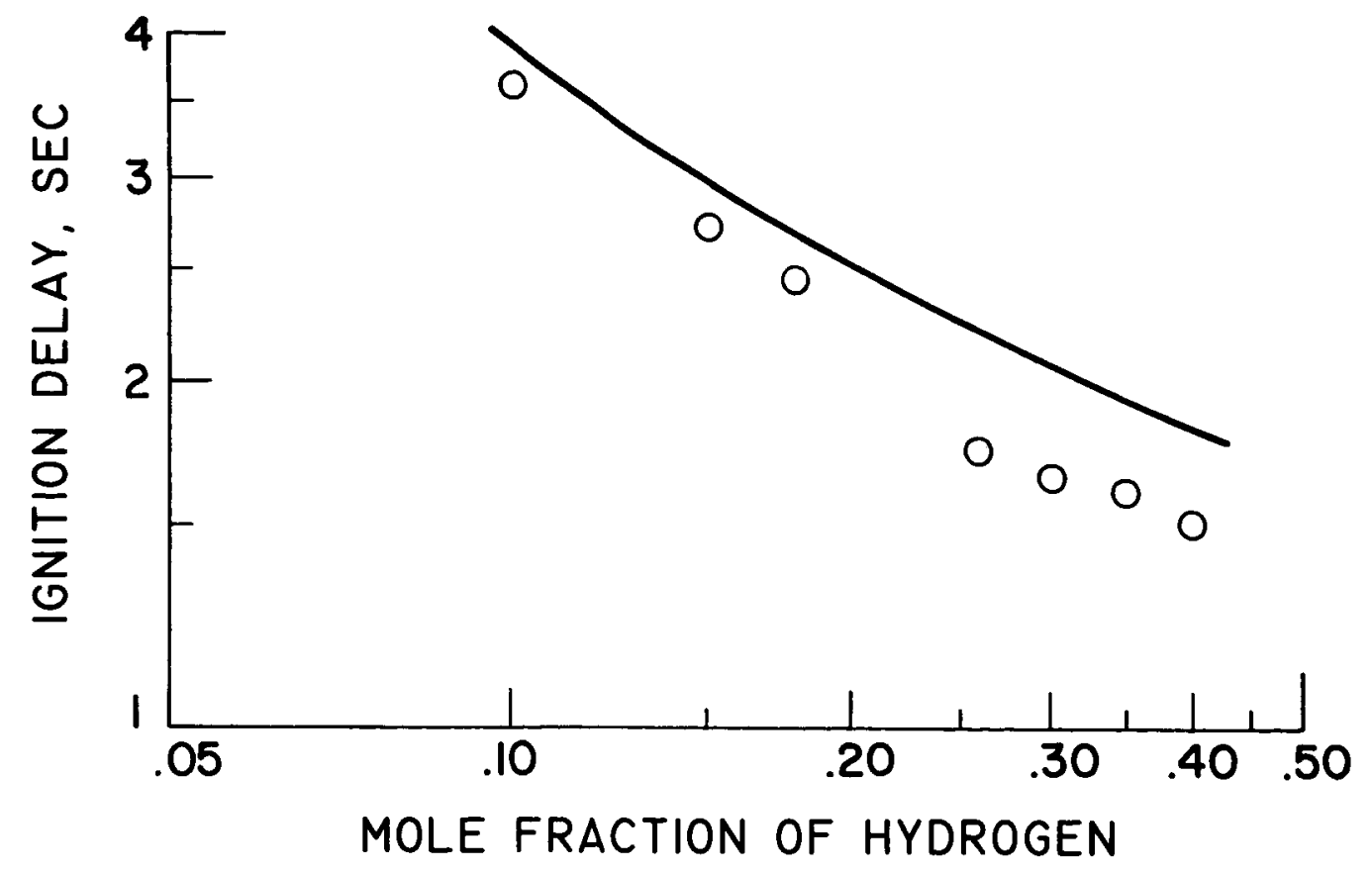

Fig. 2. - Effect of hydrogen concentration on hydrogen-air ignition delays ${ }^{11}$ at $594^{\circ} \mathrm{C}$ and $\mathrm{l}$ atmosphere. 


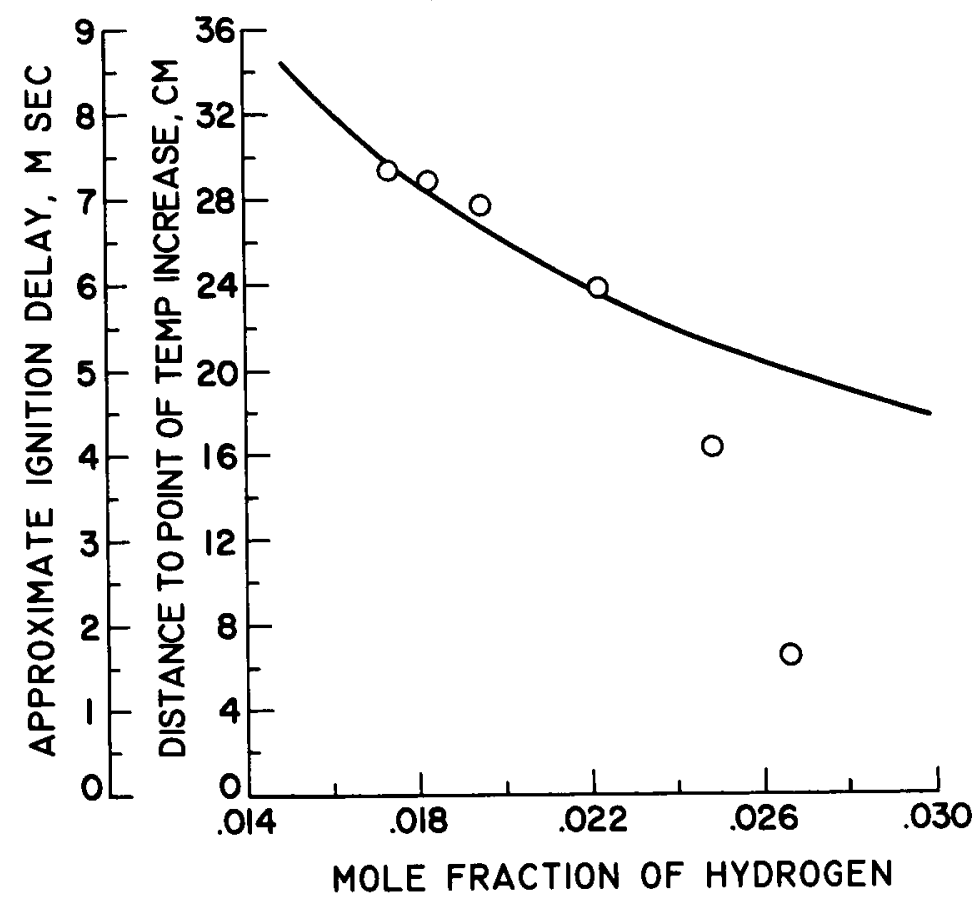

Fig. 3. - Effect of hydrogen concentration on hydrogenair ignition delay 12 for $658 \pm 2^{\circ} \mathrm{C}$ and 1 atmosphere.

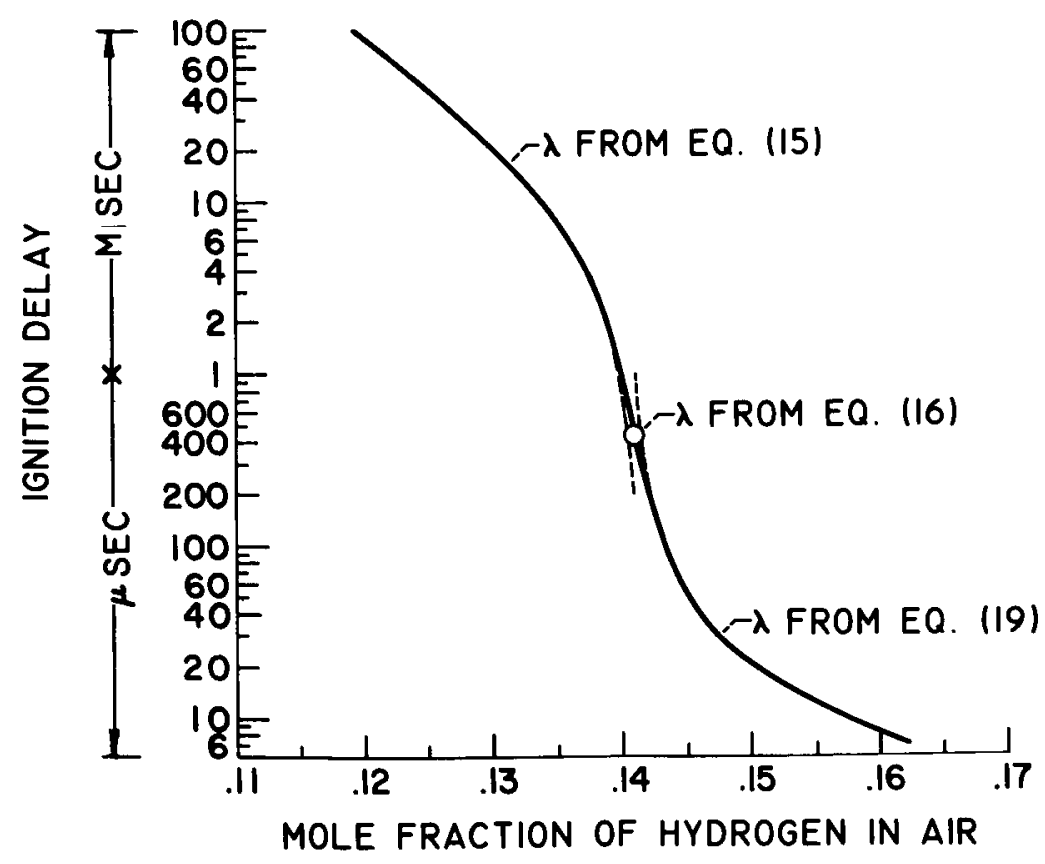

Fig. 4. - Ignition delays for the Von Neumann spike condition in Chapman-Jouguet detonations of hydrogen-air in the neighborhood of the lean limit of detonability. 